\title{
Public access defibrillation: the road ahead
}

\author{
Axel YC Siu *, FHKCEM, FHKAM (Emergency Medicine) \\ Resuscitation Council of Hong Kong, Room 809, HKAM Jockey Club Building, 99 Wong Chuk Hang Road, Aberdeen, Hong Kong
}

*Corresponding author: siuyca@ha.org.hk

Hong Kong Med J 2017;23:554-5

DOI: 10.12809/hkmj175074

Hong Kong is regarded as one of the cities with the most advanced medical technology. The survival for out-of-hospital cardiac arrest (OHCA), however, remains far from ideal. From a series in 20122013 , only $2.3 \%$ of all OHCA patients survived to discharge, a rate considered low compared with other developed countries in Asia. ${ }^{1,2}$ Meanwhile, the survival-to-discharge rate for OHCA in Singapore has doubled over the last 10 years because of the improved emergency medical services response time and the successful public access defibrillation (PAD) programme. $^{3}$

Early defibrillation is one of the most important elements in the Chain of Survival. ${ }^{4}$ Hong Kong has had a PAD programme for more than 20 years although there are no formal statistics for the number of automatic external defibrillators (AEDs). According to an estimation of one of the AED locator mobile app developers, there are approximately 5000 AEDs installed in publicly accessible areas. This is only one quarter of the number per population in Japan. ${ }^{5}$ Nonetheless, number of AEDs installed is not the only factor that dictates the success or not of a PAD programme. The accessibility of the AED will affect the time to first defibrillation. In other countries, AEDs can be accessed by anyone. They can be found in convenience stores, vending machines, and even in taxis. On the contrary, a number of AEDs in Hong Kong can be accessed only via security staff or customer service personnel. This indirect approach will inevitably delay the time to first defibrillation. Even worse, despite the established benefit of AED in early defibrillation, misconceptions remain about individual liability when using an AED. This is evidenced by the disclaimer, which restricts use of AEDs to trained persons, that accompanies some locally installed AEDs.

Despite the availability of AEDs, a PAD programme is doomed to failure if AEDs are not used. A local study showed that public knowledge about AEDs was inadequate and fewer than $20 \%$ of respondents to a survey would use one. ${ }^{6}$ The lack of enactment of a Good Samaritan law may not reassure members of the public about possible liability when using an AED, even though they are designed to be operated by a layperson. On 1 October 2017, Mainland China enacted this law under Cap 184 of the Civil Law of the People's Republic of China.?
There is a real need for Hong Kong to explore a similar enactment. We should also consider broadening the spectrum of cardiopulmonary resuscitation (CPR) and AED promulgation, eg mandatory CPR and AED training in secondary schools to teach this lifesaving skill and relieve anxiety about initiating help.

Scientific research can also facilitate the PAD programme. In Singapore, national data revealed that the majority of OHCAs occur at home. The government responded by installing AEDs in all public housing estates. ${ }^{8}$ Lack of a territory-wide cardiac arrest registry and AED registry in Hong Kong may affect the cost-effectiveness of the PAD programme. The study by Fan et $\mathrm{al}^{1}$ is a good start but we need a continuous registry, like the Cancer Registry, to observe the ongoing trend of cardiac arrests.

At an international level, the Global Resuscitation Alliance (GRA) was established in 2016 and comprised a group of international experts in resuscitation. It aimed to improve the survival of OHCA by modifying the system in the community for response to an OHCA. Establishing a PAD programme was one of the 10 steps identified by the GRA for improving survival. ${ }^{9}$ At a local level, we need a strategic plan for a PAD programme, including using local OHCA data to coordinate the placement of AEDs as well as establishment of an AED registry. Together, these will facilitate technological advances such as a mobile phone app and enhance the accessibility of AED. ${ }^{10}$ The Resuscitation Council of Hong Kong was established in 2012 with the aim of promoting CPR and AED in the community. As well as routine public promotion activities, the Council also advocated relevant policy change in Hong Kong to promote a CPR- and AED-friendly environment. In the near future, the Council will focus on the establishment of an electronic AED Registry and enactment of the Good Samaritan law. ${ }^{11}$

\section{Declaration}

The author has disclosed no conflicts of interest.

\section{References}

1. Fan KL, Leung LP, Siu YC. Out-of-hospital cardiac arrest in Hong Kong: a territory wide study. Hong Kong Med J 2017;23:48-53.

2. Ong ME, Shin SD, De Souza NN, et al. Outcomes for out-of-hospital cardiac arrests across 7 countries in Asia: 
The Pan Asian Resuscitation Outcomes Study (PAROS). Resuscitation 2015;96:100-8.

3. Lai $\mathrm{H}$, Choong $\mathrm{CV}$, Fook-Chong $\mathrm{S}$, et al. Interventional strategies associated with improvements in survival for out-of-hospital cardiac arrests in Singapore over 10 years. Resuscitation 2015;89:155-61.

4. Kleinmann ME, Brennan EE, Goldberger ZD, et al. Part 5: Adult basic life support and cardiopulmonary resuscitation quality. 2015 American Heart Association guidelines update for cardiopulmonary resuscitation and emergency cardiovascular care. Circulation 2015;132(18 Suppl 2):S41435 .

5. Iwami T. Effectiveness of public access defibrillation with AEDs for out-of-hospital cardiac arrests in Japan. Japan Med Assoc J 2012;55:225-30.

6. Fan KL, Leung LP, Poon HT, Chiu HY, Liu HL, Tang WY. Public knowledge of how to use an automatic external defibrillator in out-of-hospital cardiac arrest in Hong Kong. Hong Kong Med J 2016;22:582-8.

7. 中華人民共和國民法總則. Available from: http://www. npc.gov.cn/npc/xinwen/2017-03/15/content_2018907. htm. Accessed 1 Oct 2017.

8. Lee CY, Anatharaman V, Lim SH, et al. Singapore Defibrillation Guidelines 2016. Singapore Med J 2017;58:354-59.

9. Resuscitation Academy. 10 Steps for improving survival from sudden cardiac arrest. Available from: http://www. resuscitationacademy.org/downloads/ebook/TenStepsforI mprovingSurvivalFromSuddenCardiacArrest-RA-eBookPDFFinal-v1_2.pdf. Accessed 18 Sep 2017.

10. Fan KL, Lui CT, Leung LP. Public access defibrillation in Hong Kong in 2017. Hong Kong Med J 2017;23:635-40.

11. Wai AK. Protection of rescuers in emergency care: where does Hong Kong stand? Hong Kong Med J 2017;23:656-7. 